\title{
Resilience in LGB Youths: A Systematic Review of Protection Mechanisms ${ }^{1}$
}

\author{
Daniela Fonseca Freitas ${ }^{2}$ \\ Universidade do Porto, Porto, \\ Portugal
}

\author{
Susana Coimbra \\ Universidade do Porto, Porto, Portugal \\ Anne Marie Fontaine \\ Universidade do Porto, Porto, Portugal
}

\begin{abstract}
Given the mental health disparities among LGB and heterosexual youth, literature has increasingly emphasized the need to identify the mechanisms that promote resilience among sexual minorities. This systematic review sought to answer the question: what are the protection mechanisms against homophobia among LGB youth? Of the 147 references located in the search, 13 studies were analyzed. The identified protection mechanisms were organized by two criteria: specific to sexual orientation or general, and considered to be at the personal, relational and contextual level. Most of the mechanisms revealed to solely promote the positive adjustment in the presence of risk. General protective mechanisms frequently revealed to be more compensatory of the risks than those specific to sexual orientation.
\end{abstract}

Keywords: resilience (psychology), homophobia, bullying, sexual orientation, victimization

\section{Resiliência em Jovens LGB: Uma Revisão Sistemática de Mecanismos de Proteção}

\begin{abstract}
Resumo: Considerando as disparidades observadas em diversos indicadores de ajustamento entre jovens lésbicas, gay e bissexuais (LGB) e jovens heterossexuais, revelou-se importante identificar os mecanismos que promovem a resiliência das minorias sexuais. Por meio de uma revisão sistemática, procurou-se responder à questão: quais são os mecanismos de proteção perante a homofobia junto dos jovens LGB? Das 147 referências localizadas na pesquisa sistemática, 13 estudos foram analisados. Os mecanismos de proteção identificados foram organizados de acordo com dois critérios: especificidade (serem gerais ou específicos à orientação sexual) e nível (pessoais, relacionais ou contextuais). Os resultados demonstram que a maioria destes mecanismos são unicamente promotores do ajustamento positivo na presença do risco. Os mecanismos gerais revelaram-se mais frequentemente compensatórios dos riscos do que os específicos.
\end{abstract}

Palavras-chave: resiliência (psicologia), homofobia, bullying, orientação sexual, vitimização

\section{Resiliencia en los Jóvenes LGB: Una Revisión Sistemática de los Mecanismos de Protección}

\begin{abstract}
Resumen: Considerando las disparidades observadas en varios indicadores de ajuste entre jóvenes gais, lesbianas y bisexuales y jóvenes heterosexuales, ha sido enfatizada en la literatura la necesidad de identificar los mecanismos que promueven la resiliencia entre las minorías sexuales. Esta revisión sistemática trató de responder la pregunta: ¿cuáles son los mecanismos de protección contra la homofobia entre los jóvenes LGB? De las 147 referencias localizadas en la búsqueda sistemática, 13 estudios fueron analizados. Los mecanismos de protección identificados fueron ordenados según dos criterios: específicos a la orientación sexual o generales, y considerando su nivel de expresión: personales, relacionales o contextuales. Los resultados demuestran que la mayoría de estos mecanismos son exclusivamente promotores del ajuste positivo en la presencia del riesgo. Los mecanismos de protección generales se revelan más a menudo compensatorios de los riesgos que los específicos.
\end{abstract}

Palabras clave: resiliencia (psicología), homofobia, bullying, orientación sexual, victimización

\footnotetext{
${ }^{1}$ The paper is part of the doctoral dissertation of the first author, made under supervision of Anne Marie Fontaine, Susana Coimbra and Edna Maria Marturano, defended in 2016 in the Doctoral Program in Psychology at the Faculty of psychology and Education Sciences of the University of Porto, in cooperation with the Graduate Program in Psychology at Ribeirão Preto School of Philosophy, Science and Literature of the University of São Paulo.

Support: This study was funded by a doctoral grant from FCT - Portuguese national funding agency for science, research and technology (SFRH/BD/79575/2011) and by an International Students USP Grant Program (2014.1.3765.1.1). This work was funded by the Portuguese Science Foundation (CPUP UID/PSI/00050/2013; FEDER/COMPETE2020 POCI-01-0145-FEDER-007294).
}

\footnotetext{
${ }^{2}$ Correspondence address:

Daniela Fonseca Freitas. Rua Alfredo Allen, 4200-135, Porto, Portugal. E-mail: daniela.ffreitas@gmail.com
} 
Lesbian, gay and bisexual (LGB) people, especially youth, have been identified as a group at psychosocial risk, manifesting weaker psychological adaptation in comparison with heterosexuals, namely higher levels of depression, anxiety, drug consumption and suicide ideas and attempts (D'Augelli, 2002; Espelage, Aragon, Birkett, \& Koenig, 2008). Many young LGB do not present any disorder though. Therefore, it is important to identify the protection mechanisms that can explain their resilience (Hatzenbuehler, 2009; Meyer, 2003; Rivers \& Cowie, 2006; Saewyc, 2011). Resilience refers to the "processes or patterns of positive adaptation and development in the context of significant threats to an individual's life or function" (Masten \& Wright, 2010 , p. 215). Thus, to be able to truly speak of resilience, both a significant risk (condition associated with the occurrence of disequilibria in a person's biopsychosocial functioning) and positive adaptation (absence of psychological disorder and/or suitable social performance) need to be present (Coimbra \& Fontaine, 2015; Masten \& Wright, 2010).

Research has demonstrated that this positive adaptation is due to the effect of protection mechanisms. These can exist at the internal (personal resources) or external (context resources) level (Coimbra \& Fontaine, 2015; Poletto \& Koller, 2008; Yunes, 2003). In function of their effects on risk, the protection mechanisms can be organized in three main groups: (a) compensatory, when they positively influence the adaptation, but do not interact with the risk; (b) protective, when they affect the relation between risk and adaptation, offsetting the effect of the former; and (c) challenging, when the levels of the risk mechanisms are optimal, without raising significant threats for the adaptation and conceding developmental opportunities (Coimbra \& Fontaine, 2015; Masten \& Wright, 2010). The dimensions that enhance the negative effect of the risk mechanisms under certain conditions have been called vulnerability mechanisms (Luthar, Cicchetti, \& Becker, 2000).

Social prejudice, which is manifested in different ways, is the main risk mechanism for LGB youth. Reviews reveal higher probabilities of suffering bullying and other violent acts in life among LGB (Fedewa \& Ahn, 2011; Katz-Wise \& Hyde, 2012). Other frequent risk mechanisms deriving from social prejudice are expected rejection, hiding one's sexual orientation and internalized homophobia (Meyer, 2003). Due to their risk exposure, LGB tend to display a more weakening pattern than heterosexuals in variables like hope, self-esteem, emotional regulation, social isolation and substance abuse (Hatzenbuehler, 2009). As regards the mechanisms that seem to favor the resilience process in LGB, the literature highlights the coping strategies used, the perceived social support, the valuation of the LGB identity (Meyer, 2003), emotional openness and an optimistic perspective towards the future (Kwon, 2013). At the relational level, the importance of positive and non-conflicting relationships was also observed, as well as the perceived acceptance in the family and school contexts (D'Augelli, 2002; Ryan, Russell, Huebner, Diaz, \& Sanchez, 2010; Saewyc, 2011; Ueno, 2005).

To contribute to the specific knowledge on the resilience process in young LGB, a systematic review of empirical studies was undertaken to answer the following question: What are the protection mechanisms against homophobia among LGB youth?

\section{Method}

\section{Study Design}

A systematic literature review was undertaken. The guidelines by Pai et al. (2004) for the systematic reviews were followed, and the PRISMA guidelines were considered to report this study (Moher, Liberati, Tetzlaff, \& Altman, 2009).

\section{Databases, Search Terms and Inclusion Criteria}

The location of relevant studies only included the search in databases. In line with the suggestions by Pai et al. (2004), studies were sought in generic databases and in specific databases in Psychology, Medicine and Educational Sciences. The bibliographic search was accomplished in June 2015, using the search engine EBSCOhost and the license of Universidade do Porto, in the following databases: Academic Search Complete, Education Source, ERIC, MEDLINE with Full Text, Psychology and Behavioral Sciences Collection, PsycINFO, SocINDEX, and Teacher Reference Center. In addition, a search was undertaken in the SciELO database.

In these search processes, keywords related to discrimination based on sexual orientation - homophobia OR homophobic OR homonegativity OR homophobic discrimination OR $L G B$ prejudice OR homosexism OR heterosexism OR sexual stigma OR homophobic bullying were combined (AND) with terms related to the theoretical framework of resilience - protective factor OR buffer OR resilience $\mathrm{OR}$ protective mechanism $\mathrm{OR}$ positive adaptation. The keywords related to discrimination should figure in the abstract, but no specification for the location for the terms related to resilience was made. No condition was established for the geographical origin of the studies, language, publication form or any sample characteristic.

For the systematic review, only empirical studies whose full text was available were included. Theoretical and documentary studies and literature reviews were excluded. To be included in the review, the empirical studies had to: (1) be quantitative; (2) include a variable that could serve as a protection mechanism and (3) be conducted in a sample of sexual minority youth or young adults.

\section{Procedure}

Data collection. According to the guidelines by Pai et al. (2004), first, the title and abstracts of the articles were analyzed, whose references had been stored in Endnote software. Next, the full text was analyzed for those studies that sufficiently complied with the inclusion criteria and for studies in which doubts arose. After reading the full article and deciding on the eligibility of the studies to answer the research question under review, the results were analyzed and summarized. 
Data analysis. After constituting the corpus, the review was based on the analysis of the statistical relationships (significant if $p<.05$ ) between the risk mechanisms (e.g., discrimination), the protection mechanisms (e.g., LGB friends) and the adaptation indicators (e.g. depression) assessed in each study.

\section{Results}

The review resulted in the identification of 147 references to independent studies. After reading the titles and abstracts, qualitative studies, theoretical articles or reviews were excluded, as well as studies that did not address the specific theme and studies whose sample did not include LGB participants (e.g. studies involving children of LGB or transgender people), resulting in the selection of 32 studies. In this group, access to the full text was not possible for seven references (mainly dissertations and books). Therefore, only 25 studies were fully read. Of these, the following were excluded: seven studies using samples of LGB adults; two that did not adopt psychological adaptation as an outcome indicator; two studies whose analyses did not permit answering the question under analysis and one abstract of a congress presentation (which was unavailable for access). Hence, 13 studies that complied with all inclusion criteria were identified.

Among the 13 studies included, 12 were published in scientific journals (Baams, Bos \& Jonas, 2014; Dunn, Gonzalez, Costa, Nardi \& Iantaffi, 2014; Kaysen, Kulesza, Balsam, Rhew, Blayney, Lehavot \& Hughes, 2014; Pearson \& Wilkinson, 2013; Ploderl, Faistauer \& Fartacek, 2010; Rivers \& Cowie, 2006; Sandfort, Bos, Knox \& Reddy, 2015; Spencer \& Patrick, 2009; Walker \& Longmire-Avital, 2013; Woodford, Kulick \& Atteberry, 2015; Woodford, Kulick, Sinco \& Hong, 2014; Woodford, Paceley, Kulick \& Hong, 2015) and one was a doctoral dissertation (Benibgui, 2011). The studies were published between 2006 and 2015 but, in one of the studies (Pearson \& Wilkinson, 2013), the data were collected in 1995 and 1996. Almost half of the studies were conducted in the United States of America (Kaysen et al., 2014; Pearson \& Wilkinson, 2013; Walker \& LongmireAvital, 2013; Woodford et al., 2015a; 2015b; 2014), although other geographical origins were also represented: United Kingdom (Rivers \& Cowie, 2006), Austria (Ploderl et al., 2010), Canada (Benibgui, 2011), The Netherlands (Baams et al., 2014), Brazil (Dunn et al., 2014) and South Africa (Sandfort et al., 2015). Two studies present data from samples that a part of the participants are the same (Woodford et al., 2015b; 2014). Most studies adopt a cross-sectional design, except for one (Pearson \& Wilkinson, 2013), in which the data used were collected with a one-year interval. Three studies use a sample that also includes heterosexuals with the purpose of comparison (Pearson \& Wilkinson, 2013; Rivers \& Cowie, 2006; Spencer \& Patrick, 2009). Only one study uses a national representing sample of the country where the study was undertaken, involving 13,140 adolescents who manifested attraction for people of the same sex (Pearson \& Wilkinson, 2013). The remainders studies use smaller and convenience samples, totaling 3,894 youth who defined themselves as gay, lesbian, bisexual, queer (LGBQ) or nor exclusively heterosexual or affirmed sexual practices with someone of the same sex. In total, the 13 studies involved 16,794 LGBQ youth.

The studies included in the systematic review revealed that most of the risk mechanisms identified (e.g., internalized homophobia, conflicts due to sexual orientation or heterosexist harassments - LGB conflicts) were significantly associated with different dimensions of psychosocial adaptation (e.g., depression or drug consumption). As the focus of this article is to identify, based on this systematic review, the dimensions that can cushion the negative impact of risk mechanisms, or promote positive psychosocial adaptation, the protection mechanisms assessed in the 13 studies will be systemized in further detail in the following part. The protection mechanisms discussed are personal, relational and contextual. In the first two categories, the specific protection mechanisms to the expression of a minority sexual orientation are distinguished from the general protection mechanisms, whose positive functions have also been discussed with regard to other types of risks.

\section{Personal Protection Mechanism specific to Sexual Orientation}

Concerning the specific personal protection mechanisms, three studies focused on aspects related to the LGB identity: identification with the LGB community (Sandfort et al., 2015), LGB pride (Woodford et al., 2014), salience of LGB identity (Woodford et al., 2015b), the use of coping strategies related to the sexual orientation (Kaysen et al., 2014) and the tendency to coming-out or omit one's sexual orientation (Dunn et al., 2014; Sandfort et al., 2015). The identification with the LGB community was neither associated, with nor did it predict, depression and anxiety (Sandfort et al., 2015). $L G B Q$ pride, on the other hand, in combination with selfesteem, was associated with lower anxiety and perceived stress (Woodford et al., 2014), also serving as a mediator of the effects of heterosexist harassments on anxiety and perceived stress (Woodford et al., 2015a). Having a salient $L G B Q$ identity (medium and high scores) annulled the negative impact of microaggressions from the distal environment but led to greater anxiety in the face of proximal environmental microaggressions (Woodford et al., 2015b). In addition, the salience of the LGBQ identity was positively correlated with self-esteem, despite not being a significant predictor. The use of coping strategies related to sexual orientation (e.g., confronting the homophobia, self-acceptance, informing on the sexual orientation) or omitting one's sexual orientation vs. coming-out was not associated either with depression (Kaysen et al., 2014; Dunn et al., 2014; Sandfort et al., 2015) or anxiety (Kaysen et al., 2014; Sandfort et al., 2015). In the participants who perceived they had little competence to solve difficult situations, however, the omission of their sexual orientation predicted depression (Dunn et al., 2014). Also, omitting one's sexual orientation was associated with greater sexual confusion and higher levels of internalized 
homophobia, which in turn predicted depressive symptoms (Sandfort et al., 2015).

\section{General Personal Protection Mechanisms}

As general personal protection mechanisms, the effects analyzed were related to self-esteem (Woodford et al., 2015a, 2014), anxious personality (Walker \& LongmireAvital, 2013), religiosity (Walker \& Longmire-Avital, 2013), perceived control, namely perceived competence to solve difficult situations and mastery (Dunn et al., 2014; Spencer \& Patrick, 2009), general coping strategies (Kaysen et al., 2014), physical exercise (Woodford et al., 2015a) and variation in cortisol levels (Benibgui, 2011). Self-esteem was a significant predictor of depression, anxiety and physical health problems in the presence of heterosexist harassments (Woodford et al., 2015a). In addition, an interaction was observed with heterosexism, whose influence on alcohol consumption is more pronounced when self-esteem is low (Woodford et al., 2015a). An anxious personality (Walker \& Longmire-Avital, 2013) was positively correlated with depressive symptoms and internalized homophobia. Religiosity (Walker \& Longmire-Avital, 2013) was correlated neither with depression nor anxiety, but positively correlated with internalized homophobia. The perceived control, specifically the perceived competence to solve difficult situations, was systematic and negatively correlated with internalized homophobia and depression (Dunn et al., 2014; Walker \& Longmire-Avital, 2013) and inhibited the influence of internalized homophobia, depression (Dunn et al., 2014). The other dimension of perceived control, perceived mastery, together with social support, inhibited the influence of the risk associated with the minority sexual orientation on depression and revealed to be a significant predictor of self-esteem (Spencer \& Patrick, 2009).

As regards the general coping strategies (Kaysen et al., 2014), the maladaptive strategies (such as self-blame, behavioral disinvestment, denial and drug use) revealed a mediating role in the effect of internalized homophobia on depression and anxiety. In addition, the use of adaptive coping strategies (planning, active coping, positive reinterpretation, search for emotional support) was not associated with depression or anxiety, nor were explained internalized homophobia. Physical exercise demonstrated no correlation with alcohol abuse and physical health. Only as from a certain intensity level (at least four times per week) did it inhibit the effects of heterosexism on depression and anxiety (Woodford et al., 2015a). Another protection mechanism studied was the variation in cortisol levels throughout the day, in which it was verified that the experiences of homophobic victimization and LGB conflicts only predicted depression in case of disrupted cortisol levels (Benibgui, 2011). The presence of social support also reduced the effect of cortisol disruption on depression. No associations were observed between cortisol variation and anxiety or self-esteem.

\section{Specific Relational Protection Mechanisms}

At this level, the number of friends who share the same sexual orientation (Ploderl at al., 2010; Woodford et al., 2015a), other people's reactions to the coming-out and the perceived acceptance at school were considered (Ploderl at al., 2010). Having friends, and LGB friends functioned as a protection mechanism in both studies in which it was assessed (Ploderl at al., 2010; Woodford et al., 2015a). In one (Ploderl at al., 2010), having LGB colleagues or professors, although not associated with suicidal ideas, contributed to a higher perceived acceptance at school. In the other study, involving college youth (Woodford et al., 2015a), the number of LGB friends by itself did not predict variations in depression, anxiety and physical health. Nevertheless, in people with at least four LGB friends, this network of relationships reduced the predictive power of heterosexist harassments on students' alcohol abuse.

Peers' reactions to, or expectations concerning the coming-out, when positive or neutral, were associated with less suicide ideas and attempts (Ploderl at al., 2010). Regarding the teachers, however, only the negative reactions were associated with suicidal ideas (Ploderl at al., 2010). When the perceived acceptance in school was low, it was observed that the victimization by colleagues and the victimization based on non-gender compliance were more associated with suicidal ideas (Ploderl at al., 2010).

\section{General Relational Protection Mechanisms}

The non-specific protection mechanisms studied were social support (Benibgui, 2011; Rivers \& Cowie, 2006; Sandfort et al., 2015; Spencer \& Patrick, 2009), relationship with the parents (Benibgui, 2011; Pearson \& Wilkinson, 2013), being in a romantic relationship (Baams at al., 2014) and positive relations with the professors (Woodford et al., 2015a). In the four studies (Benibgui, 2011; Rivers \& Cowie, 2006; Sandfort et al., 2015; Spencer \& Patrick, 2009) that explored social support, it was observed that higher levels of support were associated with lower levels of depressive symptoms (Benibgui, 2011; Rivers \& Cowie, 2006; Spencer \& Patrick, 2009), equaling the depression levels between LGB youth and heterosexuals (Spencer \& Patrick, 2009). Nevertheless, social support did not cushion the influence of LGB conflicts, internalized homophobia or homophobic victimization (Benibgui, 2011). It was also observed that, when social support was high, the LGB conflicts did not predict depression. In addition, it was observed that support only negatively predicted depression when the levels of internalized homophobia were high (Benibgui, 2011). Overall, no linear association was observed between social support and anxiety (Benibgui, 2011; Rivers \& Cowie, 2006; Sandfort et al., 2015) and suicidal ideas (Benibgui, 2011; Rivers \& Cowie, 2006). Contrary to expectations, it was observed that people with high levels of victimization in the course of life manifested less suicidal ideas when they also received less social support (Benibgui, 2011). Nevertheless, social support constant and positively predicted self-esteem (Benibgui, 2011; Spencer \& Patrick, 2009), even when the regression included experiences of LGB conflicts and the homophobic 
victimization experienced by LGB youth (Benibgui, 2011), and the non-heterosexual orientation in a study that involved a heterogeneous sample (Spencer \& Patrick, 2009). The lack of social support and conflicts related to sexual orientation were the main predictors of internalized homophobia, even in and presence of other forms of homophobic victimization or positive parental relationship (Benibgui, 2011).

The relationship with the parents was included in two studies (Benibgui, 2011; Pearson \& Wilkinson, 2013). In one, the perceived support, union and engagement in activities with the parents negatively predicted depression (Pearson \& Wilkinson, 2013). In the other (Benibgui, 2011), it was observed that, only in youth with low levels of internalized homophobia, the positive relationship with the parents significant and negatively predicted depression and anxiety. It was also verified that this positive relationship was the weakest predictor of suicidal ideas, in a regression that considered the risk mechanisms associated with being LGB and social support (Benibgui, 2011). In addition, it revealed to be the main predictor of self-esteem (Benibgui, 2011). The family relationships characterized by less union and support were also associated with drug consumption in a heterogeneous sample in terms of sexual orientation (Pearson \& Wilkinson, 2013). In addition, interactions with gender and sexual orientation were observed concerning drug consumption and running away from home (Pearson \& Wilkinson, 2013). In lesbian and bisexual girls, running away from home were only associated with perceived low parental support. In gay and bisexual boys, beyond the low perceived support, it was observed that participating in activities with the family was associated with greater drug consumption and running away from home, while this engagement had a protective effect for heterosexual boys (Pearson \& Wilkinson, 2013).

The engagement in a romantic relationship was discussed in one study, which included minority stress as a risk mechanism. Being in a romantic relationship did not predict well-being, but inhibited the negative effect of expected rejection on well-being (Baams et al., 2014). The positive relationship with college professors was positively correlated with self-esteem and the perception of support for sexual on campus minorities A positive relationship was associated with heterosexist harassments and with reports of bad physical health, reducing the risk of depression, and anxiety (Woodford et al., 2015a). In addition, interaction was observed with heterosexism to predict physical health: for low or medium levels of heterosexism, having positive relationships with the teachers reduces its impact on physical health (Woodford et al., 2015a). No association was found between the quality of these relationships and alcohol abuse in the college participants (Woodford et al., 2015a).

\section{Contextual Protection Mechanisms to Sexual Minorities}

All the contextual protection mechanisms reported in the selected studies are specific to sexual orientation, namely the recognition of the diversity of sexual orientation in the school context (Ploderl at al., 2010), the perceived attitudes of support for LGB people (Woodford et al., 2015a), the equalitarian legislation regarding marriage, the protection of LGBT people on the job (Woodford et al., 2015b). The recognition of the diversity in the sexual orientation in the school context was assessed through different items, such as: the interventions of teachers against homophobia, the presence of colleagues, teachers and other technicians that participants could talk to about sexual orientation, the presence of books or leaflets about homosexuality, or the integration of sexual orientation in the classroom by teachers or by LGB adult speakers. Although no associations were observed between these elements and the suicide attempts, they, and the presence of openly LGB colleagues or teachers, contributed to the perceived acceptance in school, which in turn was negatively associated with the suicide ideas (Ploderl at al., 2010). In the college context, perceived attitudes of support for sexual minorities were not correlated with depression, anxiety, alcohol abuse or physical health (Woodford et al., 2015a). However, they were related with higher with self-esteem, a positive relationship with the teachers, and less heterosexists harassments (Woodford et al., 2015a).

At the legislative level, the access to same-sex marriage (variable deduced from the state where the college students lived in the USA) and the protection of LGBT at work did not predict anxiety levels and perceived stress (Woodford et al., 2015b). The access to marriage, however, is a significant predictor of self-esteem and, against expectations, the results indicate that participants who live in states with equalitarian legislation manifest lower self-esteem. This effect is stronger in people with high levels of salience of the LGBQ identity. The protection at work predicted higher self-esteem scores for all participants (Woodford et al., 2015b).

As the objective in this study was to identify the protection mechanisms among LGB youth, the information collected was categorized in function of the type of protection demonstrated according to the technical framework of resilience, namely as compensatory, protective and vulnerability mechanisms (Coimbra \& Fontaine, 2015; Luthar et al., 2000; Masten \& Wright, 2010). The result of this integration is displayed in Table 1. 
Table 1

Protection and Vulnerability Mechanisms in Young LGB

\begin{tabular}{|c|c|c|c|}
\hline & Protective Mechanisms & Non-Protective Mechanisms & $\begin{array}{l}\text { Vulnerability } \\
\text { Mechanisms }\end{array}$ \\
\hline 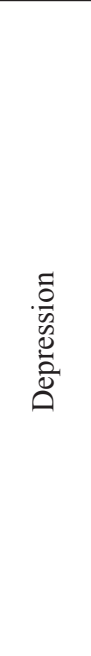 & $\begin{array}{l}\text { Self-esteem (compensatory and mediator of heterosexism) } \\
\text { Perceived competence in solving difficult situations } \\
\text { (protective, offsets the risk of internalized homophobia) } \\
\text { Perceived mastery (compensatory) } \\
\text { Physical exercise (protective-stabilizing effect on } \\
\text { heterosexism) } \\
\text { Social support (compensatory; protective-stabilizing } \\
\text { effect of cortisol disruption; protective-stabilizing } \\
\text { effect of LGB conflicts; protective-stabilizing effect of } \\
\text { internalized homophobia) } \\
\text { Positive relationship with the parents (compensatory, } \\
\text { protective-stabilizing effect of internalized } \\
\text { homophobia) Pupport, union with the parents and engagement } \\
\text { Perceived supporth } \\
\text { in activities with the parents (compensatory) } \\
\text { Positive relationships with professors in college } \\
\text { (compensatory of heterosexism" após compensatory) }\end{array}$ & $\begin{array}{l}\text { Identification with LGBQ community } \\
\text { Openness to coming-out } \\
\text { LGB coping } \\
\text { Number of LGB friends } \\
\text { Perceived attitudes of support to sexual } \\
\text { minorities in college context } \\
\text { Adaptive coping } \\
\text { Social support (non-protective effect on } \\
\text { homophobic discrimination) }\end{array}$ & $\begin{array}{l}\text { Maladaptive coping } \\
\text { (vulnerability } \\
\text { and mediator } \\
\text { of internalized } \\
\text { homophobia) } \\
\text { Cortisol disruption } \\
\text { (reactive } \\
\text { vulnerability to } \\
\text { victimization and } \\
\text { LGB conflicts) }\end{array}$ \\
\hline 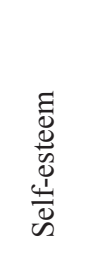 & $\begin{array}{l}\text { Protection at work (compensatory of microaggressions) } \\
\text { Perceived mastery (compensatory) } \\
\text { Social support (compensatory of homophobic victimization } \\
\text { and LGB conflicts) } \\
\text { Positive relationship with the parents (protective, offsets } \\
\text { the influence of internalized homophobia, homophobic } \\
\text { victimization and LGB conflicts) }\end{array}$ & & $\begin{array}{l}\text { Equalitarian legislation } \\
\text { of marriage (reactive } \\
\text { vulnerability to high } \\
\text { levels of LGB iden- } \\
\text { tity salience) }\end{array}$ \\
\hline $\begin{array}{l}\stackrel{\lambda}{.0} \\
\stackrel{0}{x} \\
\stackrel{2}{<}\end{array}$ & $\begin{array}{l}\text { LGB pride (compensatory and mediator of heterosexism) } \\
\text { Salience of LGBQ identity (compensatory and protective- } \\
\text { stabilizing effect of distal microaggressions) } \\
\text { Self-esteem (compensatory and mediator of heterosexism) } \\
\text { Physical activity (protective-stabilizing effect on } \\
\text { heterosexism) } \\
\text { Positive relationship with the parents (protective- } \\
\text { stabilizing effect on internalized homophobia) } \\
\text { Positive relations with professors in college (compensatory } \\
\text { of heterosexism) }\end{array}$ & $\begin{array}{l}\text { Identification with LGBQ community } \\
\text { Openness to coming-out } \\
\text { LGB coping } \\
\text { Number of LGB friends } \\
\text { Perceived attitudes of support for sexual } \\
\quad \text { minorities in college context } \\
\text { Equalitarian legislation of marriage } \\
\text { Protection at work } \\
\text { Social support } \\
\text { Adaptive coping }\end{array}$ & $\begin{array}{l}\text { Maladaptive coping } \\
\text { (m. of vulnerability } \\
\text { and mediator } \\
\text { of internalized } \\
\text { homophobia) } \\
\text { Salience of LGBQ } \\
\text { identity (reactive } \\
\text { vulnerability } \\
\text { to proximal } \\
\text { microaggressions) }\end{array}$ \\
\hline 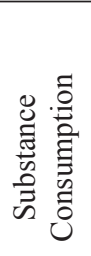 & $\begin{array}{l}\text { Number of LGB friends (protective-stabilizing effect on } \\
\text { heterosexism) } \\
\text { Self-esteem (protective-reactive to heterosexism) } \\
\text { Perceived union and support by parents (compensatory) } \\
\text { Engagement in activities with the parents (compensatory } \\
\quad \text { in female adolescents - LB }\end{array}$ & $\begin{array}{l}\text { Perceived attitudes of support to sexual } \\
\text { minorities } \\
\text { Physical exercise } \\
\text { Positive relationships with professors in } \\
\text { college }\end{array}$ & $\begin{array}{l}\text { Engagement in activi- } \\
\text { ties with the parents } \\
\text { (vulnerability only } \\
\text { in male adolescents } \\
\text { - GB) }\end{array}$ \\
\hline 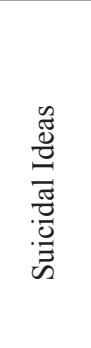 & $\begin{array}{l}\text { Positive reactions to coming-out by peers } \\
\text { Positive relationship with parents (compensatory in the } \\
\text { presence of internalized homophobia, homophobic } \\
\text { victimization and LGB conflicts) }\end{array}$ & $\begin{array}{l}\text { Positive reactions to coming-out by } \\
\text { teachers } \\
\text { Presence of LGB friends or teachers } \\
\text { Elements of recognition of sexual diversity } \\
\quad \text { in school } \\
\text { Social support }\end{array}$ & $\begin{array}{l}\text { Negative reactions by } \\
\text { teachers to coming- } \\
\text { out } \\
\text { Non-acceptance at } \\
\text { school } \\
\text { Social support } \\
\text { (vulnerability } \\
\text { reactive to } \\
\text { victimization) }\end{array}$ \\
\hline
\end{tabular}




\section{Discussion}

The results indicate that the mechanisms specific to sexual orientation play a protective or compensatory function of risk (observed in only six of the 13 variables studied) to a lesser extent than the general mechanisms (found in 11 of the 15 variables studied). Concerning the specific protection mechanisms, the literature suggests that positive affect towards the minority group and identification with that group does not constantly cushion the effects of discrimination in mental and physical health and, in some situations, even exacerbates the effects of the discrimination (Schmitt, Branscombe, Postmes, \& Garcia, 2014). Similar results were observed in this review. Among the specific protection mechanisms studied, the majority did not reveal any protective function against symptoms of depression or anxiety. Only protection at work seems to have some effect on self-esteem. Nevertheless, although high levels of these variables have a very limited effect on the adaptation, not fulfilling their protective function, low levels of the same variables act as vulnerability mechanisms.

As an example, it is interesting to observe that the teachers' reactions, when negative, have a decisive and negative influence on psychological adaptation, namely through the perceived non-acceptance at school, which in turn is associated with suicide ideas and attempts (Ploderl et al., 2010). The professors' positive reactions do not have the corresponding significant protective effect. Other studies also evidenced the more marked influence of the negative interactions on mental health in comparison with the positive interactions (Freitas, D'Augelli, Coimbra, \& Fontaine, 2016). In this particular situation, when manifested by acquaintances, the negative reactions possibly strengthen either the existing discrimination or its attribution to internal, stable and uncontrollable factors, which can contribute to the lack of hope on different reactions in the future (Schacter, White, Chang, \& Juvonen, 2015; Schmitt et al., 2014).

As regards the contextual mechanisms, only the promotive function of self-esteem on the protection at work of LGB was observed. The other political devices including sexual orientation not only did not reveal their direct influence, but also have an exacerbating effect: the people who lived in states with access to marriage and whose LGB identity was salient manifested less self-esteem than the people in states without access to marriage (Woodford et al., 2015b). This result was in contradiction with other studies, in which it is observed that living in a state with discriminatory legislation is associated with a higher level of psychiatric disorders (Hatzenbuehler, McLaughlin, Keyes, \& Hasin, 2010). Several explanatory hypotheses can be considered, among which three are highlighted. In the first place, this result can be related with the age of the, college students, as they do not value marriage (yet) and may even consider it a heterosexist institution (Woodford et al., 2014). This hypothesis of valuation of the policies that are coherent with the participants' personal projects is sutained by the observation that protection measures at work promotes selfesteem of the college students. Therefore, future studies should explore the associations between the public policies and their influence on the adaptation of LGB in different phases of their lifecycle. In the second place, it is important to underline that, in the study, the impact of the equalitarian legislation on environmental microaggression was not assessed. Other studies have revealed that actions that promote the visibility of LGB can also increase their stress (Ploderl et al., 2010). The salience of the LGBQ identity also revealed to be a reactive vulnerability mechanism to the microaggression of the proximal environment resulting in higher anxiety levels (Woodford at el., 2015a). Hence, having a salient LGB identity and living in a state with equalitarian legislation can be associated with other risk mechanisms that were not taken into account in the study, such as the probability of greater discrimination, especially at the initial moments in the implementation of this legislation (Rostosky, Riggle, Horne, \& Miller, 2009). Thus, on the whole, the review results suggest that the specific protection mechanisms of minority sexual orientation seem to be beneficial only under certain conditions and for certain domains of adaptation. That does not mean that these specific protection mechanisms should be neglected. This limitation can be due to transitory contextual and/or developmental characteristics.

Among the general relational protection mechanisms, the positive relationship with the parents stood out as a general protection mechanism whose effect was more important. It cushioned the impact of homophobic victimization, LGB conflicts and internalized homophobia on suicide ideas and self-esteem. Hence, the positive relationship with the parents (Benibgui, 2011), and particularly the feeling of union and perceived parental support (Pearson \& Wilkinson, 2013) revealed to be one of the promotion and protection mechanisms related to the larger number of internal and external adaptation indicators. This information is in accordance with what has been appointed in the literature that underlines the influence of parental relations in different dimensions of the adaptation (Bouris et al., 2010; Freitas et al., 2016).

Nevertheless, a situation was observed in which the greater involvement in family activities was associated with higher illegal drugs consumption and run aways from home only in male gay and bisexual youth. The fact that these activities usually take place in heteronormative contexts can explain this atypical result, as the social expectations regarding sexuality and gender are more demanding for male people. Due to great social emphasis on masculinity, male youth who feel attracted to people of the same sex are more sensitive to social pressure and heterosexist prejudice (Gato, Carneiro, \& Fontaine, 2011; Pearson \& Wilkinson, 2013).

In sum, most studies suggest that having supportive relations with the parents and their acceptance of the sexual orientation promote a positive adaptation (Bouris et al., 2010; Pearson \& Wilkinson, 2013; Ryan et al., 2010). The adaptation process of the families to the youth's nonheterosexuality demands some time. Due, due to the stigma of the sexual orientation, any actual or anticipated negative 
reaction to the coming-out can negatively affect the youth, putting them at risk of internal and external maladaptation (Bouris et al., 2010; Ryan et al., 2010). In future studies, it is important to control the state of coming-out towards the family, if it has already happened and how long ago, in order to verify its effect on the family relations and on the youth's adaptation.

Although social support is a frequently studied dimension when facing adversity, the results of this review demonstrate that social support gained a protective or compensatory function of risk only in a small number of conditions, namely in depressive symptoms (and not in all Studies) and self-esteem. These results are in line with what is observed in other studies, in which the exacerbating influence of the impact of discrimination had already been reported (Hatzenbuehler, 2009; Luthar et al., 2000; Meyer, 2003; Schmitt et al., 2014). The hypothetic influence of the methodological aspects of the small number of studies that present an exacerbating effect, and of the different way in which social support was measured cannot be set aside (Schmitt et al., 2014). Another explanatory hypothesis considered is the possibility that the participants' reference persons who support them also manifest prejudice, thus strengthening the discrimination (Benibgui, 2011). In addition, in the particular case of the youth with high levels of victimization and social support, the conviction that benefitting from social support by itself does not reduce the victimization experienced or the negative impact of violence on them may have been induced. Finally, this result may also be interpreted within the resilience development challenge model: the confrontation with moderate doses of stress permits the improvement of personal competences that, in situations of overprotection, could be inhibited (Coimbra \& Fontaine, 2015; Masten \& Wright, 2010).

Concerning the individual general protection mechanisms, the results regarding the effect of the perceived control and competence on the solution of difficult situations and mastery are underlined. These are also consistent with the hypothesis of the challenge model and revealed to minimize the risk of depression associated with minority sexual orientation and internalized homophobia (Dunn et al., 2014; Spencer \& Patrick, 2009). Personal agency is, by the way, a privileged protection mechanism in resilience to adversity (Coimbra \& Fontaine, 2015; Masten \& Wright, 2010), with direct and indirect effects on the use of more adaptive coping strategies.

At the individual level, it was also observed that the use of maladaptive coping strategies, such as self-blaming and disinvestment, represent a vulnerability mechanism for the youth (Kaysen et al., 2014). These results are coherent with the literature, which has appointed the harmful effect of using passive or emotion-focused coping strategies on mental health in view of the discrimination (Luthar et al., 2000; Schmitt et al., 2014). Also in line with the review results, it was only observed in a small number of other studies that the use of active coping strategies cushions the effects of social prejudice (Schmitt et al., 2014).

On the whole, this systematic review reveals the whole complexity of the experience of a non-heterosexual orientation and the range of protection mechanisms that can be associated with the emergence of processes of resilience. It is highlighted that the association between the protection mechanisms and the adaptation indicators is rarely linear or constant, as most of the mechanisms studied only gain a protective function under specific conditions and cumulatively with other mechanisms.

It was verified, however, that there are protective mechanisms the intervention could enhance in order to improve the mental health of LGB youth. The interventions should gain systemic characteristics, with political, school, family and individual actions suitable to the context and specific developmental characteristics. In that sense, it is important to adopt strategies that promote a safe school context for the LGB youth (Fletcher \& Russell, 2001).

Despite these results, some limitations should be considered. At this level, it is emphasized that the exclusive inclusion of studies that explicitly mentioned terms related to resilience and protection mechanisms/factors may have lead to the non-consideration of studies with dimensions that could reveal their protective role and were not identified as such. On the other hand, this option had the advantage of focusing on publications specifically designed to study resilience in LGB youth. Not all studies present regressions to explain the adaptation indicators, presenting inferences only based on correlations. In addition, the predictions authorized by the regressions should be understood in the statistical sense of the term, without the possibility to fully clarify the causal relationship, given the cross-sectional nature of most studies. In addition, the majority of the studies use convenience samples, which limits the generalization of the results observed. In view of the studies included in the review, no analysis was possible that took into account the intersectionality of the different identity dimensions (e.g., sexual orientation, gender, ethnic origin, socioeconomic level). The intersectionality of several identity categories can moderate the association between the risk and protection mechanisms and determine the LGB youth's adaptation. Therefore, it deserves further attention in future studies. In addition, the review was only based on quantitative studies. Thus, a systematic analysis of qualitative studies will certainly permit the identification of other protection mechanisms not appointed in this article.

When considering the differences systematically observed in psychosocial adaptation indicators and the harmful impact of stigmatization in function of sexual orientation, it should be highlighted that no studies were found that explore the frequency of psychological therapy in the face of victimization as a protection mechanism. This gap in the literature should be studied in future research. Despite the limitations, the theoretical framework of resilience outlined in this systematic review, namely through the distinction of several types of protection mechanisms, offers a valuable contribution to design more effective social interventions in the promotion of positive adaptation for gay, lesbian, bisexual and queer youth. 


\section{References}

Baams, L., Bos, H. M. W., \& Jonas, K. J. (2014). How a romantic relationship can protect same-sex attracted youth and young adults from the impact of expected rejection. Journal of Adolescence, 37(8), 1293-1302. doi:10.1016/j.adolescence.2014.09.006

Benibgui, M. (2011). Mental health challenges and resilience in lesbian, gay, and bisexual young adults: Biological and psychological internalization of minority stress and victimization (Doctoral dissertation). Retrieved from http://spectrum.library. concordia.ca/979282/1/NR67340.pdf/

Bouris, A., Guilamo-Ramos, V., Pickard, A., Shiu, C., Loosier, P. S., Dittus, P., ... Waldmiller, J. (2010). A systematic review of parental influences on the health and well-being of lesbian, gay, and bisexual youth: Time for a new public health research and practice agenda. Journal of Primary Prevention, 31(5-6), 273309. doi:10.1007/s10935-010-0229-1

Coimbra, S., \& Fontaine, A. M. (2015). Resiliência e habilidades sociais: Reflexões conceituais e práticas para uma nova geração [Resilience and social skills: Conceptual reflections and practices for a new generation]. In Z. Del Prette, A. B. Soares, C. S. Pereira-Guizzo, M. F. Wagner, \& V. B. R. Leme (Orgs.), Habilidades sociais: Diálogos e intercâmbios sobre pesquisa e prática [Social skills: Dialogues and exchanges on research and practice] (pp. 186-220). Novo Hamburgo, RS: Sinopsys.

D’Augelli, A. R. (2002). Mental health problems among lesbian, gay, and bisexual youths ages 14 to 21 . Clinical Child Psychology and Psychiatry, 7(3), 433456. doi:10.1177/1359104502007003010

Dunn, T. L., Gonzalez, C. A., Costa, A. B., Nardi, H. C., \& Iantaffi, A. (2014). Does the minority stress model generalize to a non-U.S. sample? An examination of minority stress and resilience on depressive symptomatology among sexual minority men in two urban areas of Brazil. Psychology of Sexual Orientation and Gender Diversity, 1(2), 117-131. doi: $10.1037 / \operatorname{sgd} 0000032$

Espelage, D. L., Aragon, S. R., Birkett, M., \& Koenig, B. W. (2008). Homophobic teasing, psychological outcomes, and sexual orientation among high school students: What influence do parents and schools have? School Psychology Review, 37(2), 202-216. https://pdf. countyofdane.com/humanservices/youth/assessment surveys/2009/homophobic_teasing_psych_outcomes_ parent_influence.pdf

Fedewa, A. L., \& Ahn, S. (2011). The effects of bullying and peer victimization on sexual-minority and heterosexual youths: A quantitative meta-analysis of the literature. Journal of GLBT Family Studies, 7(4), 398-418. doi:10.1080/1550428X.2011.592968
Fletcher, A. C., \& Russell, S. T. (2001). Incorporating issues of sexual orientation in the classroom: Challenges and solutions. Family Relations, 50(1), 34-40. doi:10.1111/j.1741-3729.2001.00034.x

Freitas, D. F., D’Augelli, A. R., Coimbra, S., \& Fontaine, A. M. (2016). Discrimination and mental health among gay, lesbian, and bisexual youths in Portugal: The moderating role of family relationships and optimism. Journal of GLBT Family Studies, 12(1), 68-90. doi:10 .1080/1550428X.2015.1070704

Gato, J., Carneiro, N. S., \& Fontaine, A. M. (2011). Contributo para uma revisitação histórica e crítica do preconceito contra as pessoas não heterossexuais [Contribution to a historical and critical revisiting of prejudice against non-heterosexual people]. Crítica $e$ Sociedade: Revista de Cultura Política, 1(1), 139-167. http://www.seer.ufu.br/index.php/criticasociedade/ article/view/12542/7715

Hatzenbuehler, M. L. (2009). How does sexual minority stigma "get under the skin"? A psychological mediation framework. Psychological Bulletin, 135(5), 707-730. doi:10.1037/a0016441

Hatzenbuehler, M. L., McLaughlin, K. A., Keyes, K. M., \& Hasin, D. S. (2010). The impact of institutional discrimination on psychiatric disorders in lesbian, gay, and bisexual populations: A prospective study. American Journal of Public Health, 100(3), 452-459. doi:10.2105/AJPH.2009.168815

Katz-Wise, S. L., \& Hyde, J. S. (2012). Victimization experiences of lesbian, gay, and bisexual individuals: A meta-analysis. Journal of Sex Research, 49(2-3), 142-167. doi:10.1080/00224499.2011.637247

Kaysen, D. L., Kulesza, M., Balsam, K. F., Rhew, I. C., Blayney, J. A., Lehavot, K., \& Hughes, T. L. (2014). Coping as a mediator of internalized homophobia and psychological distress among young adult sexual minority women. Psychology of Sexual Orientation and Gender Diversity, 1(3), 225-233. doi:10.1037/ $\operatorname{sgd} 0000045$

Kwon, P. (2013). Resilience in lesbian, gay, and bisexual individuals. Personality and Social Psychology Review, 17(4), 371-383. doi:10.1177/1088868313490248

Luthar, S. S., Cicchetti, D., \& Becker, B. (2000). The construct of resilience: A critical evaluation and guidelines for future work. Child Development, 71(3), 543-562. doi:10.1111/1467-8624.00164

Masten, A. S., \& Wright, M. O. (2010). Resilience over the lifespan: Developmental perspectives on resistance, recovery, and transformation. In J. W. Reich, A. J. Zautra, \& J. S. Hall (Eds.), Handbook of adult resilience (pp. 213-237). New York, NY: Guilford.

Meyer, I. H. (2003). Prejudice, social stress, and mental health in lesbian, gay, and bisexual populations: Conceptual issues and research evidence. Psychological Bulletin, 129(5), 674-697. doi:10.1037/0033-2909.129.5.674 
Moher, D., Liberati, A., Tetzlaff, J., \& Altman, D. G. (2009). Preferred reporting items for systematic reviews and meta-analyses: The PRISMA statement. Annals of Internal Medicine, 151(4), 264-269. doi:10.7326/0003-4819-151-4-200908180-00135

Pai, M., McCulloch, M., Gorman, J. D., Pai, N., Enanoria, W., Kennedy, G., . . . Colford, J. M., Jr. (2004). Systematic reviews and meta-analyses: An illustrated, step-by-step guide. The National Medical Journal of India, 17(2), 86-95.

Pearson, J., \& Wilkinson, L. (2013). Family relationships and adolescent well-being: Are families equally protective same-sex attracted youth? Journal of Youth \& Adolescence, 42(3), 376-393. doi:10.1007/s10964012-9865-5

Ploderl, M., Faistauer, G., \& Fartacek, R. (2010). The contribution of school to the feeling of acceptance and the risk of suicide attempts among Austrian gay and bisexual males. Journal of Homosexuality, 57(7), 819841. doi:10.1080/00918369.2010.493401

Poletto, M., \& Koller, S. H. (2008). Contextos ecológicos: Promotores de resiliência, fatores de risco e de proteção [Ecological contexts: furthering resilience, risk and protection factors]. Estudos de Psicologia (Campinas), 25(3), 405-416. doi:10.1590/S0103166X2008000300009

Rivers, I., \& Cowie, H. (2006). Bullying and homophobia in UK schools: A perspective on factors affecting aesilience and recovery. Journal of Gay \& Lesbian Issues in Education, 3(4), 11-43. doi: 10.1300/ J367v03n04_03

Rostosky, S. S., Riggle, E. D. B., Horne, S. G., \& Miller, A. D. (2009). Marriage amendments and psychological distress in lesbian, gay, and bisexual (LGB) adults. Journal of Counseling Psychology, 56(1), 56-66. doi:10.1037/a0013609

Ryan, C., Russell, S. T., Huebner, D., Diaz, R., \& Sanchez, J. (2010). Family acceptance in adolescence and the health of LGBT young adults. Journal of Child and Adolescent Psychiatric Nursing, 23(4), 205-213. doi:10.1111/j.1744-6171.2010.00246.x

Saewyc, E. M. (2011). Research on adolescent sexual orientation: Development, health disparities, stigma, and resilience. Journal of Research on Adolescence, 21(1), 256-272. doi:10.1111/j.15327795.2010.00727.x

Sandfort, T., Bos, H., Knox, J., \& Reddy, V. (2015). Gender nonconformity, discrimination, and mental health among black South African men who have sex with men: A further exploration of unexpected findings. Archives of Sexual Behavior, 45(3), 661-670. doi:10.1007/s10508-015-0565-6
Schacter, H. L., White, S. J., Chang, V. Y., \& Juvonen, J. (2015). "Why me?": Characterological self-blame and continued victimization in the first year of middle school. Journal of Clinical Child \& Adolescent Psychology, 44(3), 446-455. doi:10.1080/15374416.2 013.865194

Schmitt, M. T., Branscombe, N. R., Postmes, T., \& Garcia, A. (2014). The consequences of perceived discrimination for psychological well-being: A metaanalytic review. Psychological Bulletin, 140(4), 921948. doi:10.1037/a0035754

Spencer, S. M., \& Patrick, J. H. (2009). Social support and personal mastery as protective resources during emerging adulthood. Journal of Adult Development, 16(4), 191-198. doi:10.1007/s10804-009-9064-0

Ueno, K. (2005). Sexual orientation and psychological distress in adolescence: Examining interpersonal stressors and social support processes. Social Psychology Quarterly, 68(3), 258-277. doi:10.1177/019027250506800305

Walker, J. J., \& Longmire-Avital, B. (2013). The impact of religious faith and internalized homonegativity on resiliency for black lesbian, gay, and bisexual emerging adults. Developmental Psychology, 49(9), 1723-1731. doi:10.1037/a0031059

Woodford, M. R., Kulick, A., \& Atteberry, B. (2015a). Protective factors, campus climate, and health outcomes among sexual minority college students. Journal of Diversity in Higher Education, 8(2), 73-87. doi: $10.1037 / \mathrm{a} 0038552$

Woodford, M. R., Kulick, A., Sinco, B. R., \& Hong, J. S. (2014). Contemporary heterosexism on campus and psychological distress among LGBQ students: The mediating role of self-acceptance. American Journal of Orthopsychiatry, 84(5), 519-529. doi:10.1037/ ort0000015

Woodford, M. R., Paceley, M. S., Kulick, A., \& Hong, J. S. (2015b). The LGBQ social climate matters: Policies, protests, and placards and psychological well-being among LGBQ emerging adults. Journal of Gay \& Lesbian Social Services, 27(1), 116-141. doi:1 0.1080/10538720.2015.990334

Yunes, M. A. M. (2003). Psicologia positiva e resiliência: $\mathrm{O}$ foco no indivíduo e na família [Positive psychology and resilience: Focus on The individual and families]. Psicologia em Estudo, 8, 75-84. doi:10.1590/S141373722003000300010

Daniela Fonseca Freitas holds a Ph.D. in Psychology from Universidade do Porto, in cooperation with Universidade de São Paulo.

Susana Coimbra is a Professor at Universidade do Porto.

Anne Marie Fontaine is a Full Professor at Universidade do Porto. 
Freitas, D. F., Coimbra, S., \& Fontaine, A. M. (2017). Protection Mechanisms in LGB Youths.

Received: Sep. 21, 2015

1st Revision: Feb. 20, 2016

Approved: Feb. 22, 2016

How to cite this article:

Freitas, D. F., Coimbra, S., \& Fontaine, A. M. (2017). Resilience in LGB youths: A systematic review of protection mechanisms. Paidéia (Ribeirão Preto), 27(66), 69-79. doi: 10.1590/1982-43272766201709 